\title{
Evaluation of punching shear strength of flat slabs supported on rectangular columns
}

\author{
Valery Filatov ${ }^{1, *}$ \\ ${ }^{1}$ Samara State Technical University, Institute of Architecture and Civil Engineering, \\ Molodogvardeyskaya St., 194, Samara, 443001, Russia
}

\begin{abstract}
The article presents the methodology and results of an analytical study of structural parameters influence on the value of punching force for the joint of columns and flat reinforced concrete slab. This design solution is typical for monolithic reinforced concrete girderless frames, which have a wide application in the construction of high-rise buildings. As the results of earlier studies show the punching shear strength of slabs at rectangular columns can be lower than at square columns with a similar length of the control perimeter. The influence of two structural parameters on the punching strength of the plate is investigated - the ratio of the side of the column cross-section to the effective depth of slab $\mathrm{C} / \mathrm{d}$ and the ratio of the sides of the rectangular column $\mathrm{C}_{\max } / \mathrm{C}_{\min }$. According to the results of the study, graphs of reduction the control perimeter depending on the structural parameters are presented for columns square and rectangular cross-sections. Comparison of results obtained by proposed approach and MC2010 simplified method are shown, that proposed approach gives a more conservative estimate of the influence of the structural parameters. A significant influence of the considered structural parameters on punching shear strength of reinforced concrete slabs is confirmed by the results of experimental studies. The results of the study confirm the necessity of taking into account the considered structural parameters when calculating the punching shear strength of flat reinforced concrete slabs and further development of code design methods.
\end{abstract}

\section{Introduction}

In the modern world one of the indicators of sustainable development of society and the state is the construction of high-rise buildings and structures. The construction and operation of high-rise buildings implies the possession of modern technology in all stages: from planning and design solutions, designing load-bearing structures of buildings and engineering systems, organization of construction works, to the monitoring of structures and engineering systems of the building to ensure failure-free operation [1-4].

The most common design solution when designing high-rise buildings is the use of monolithic gidderless slabs supported on columns-pylons [5-7]. Columns-pylons have rectangular cross-section whose height is several times greater than the width, which

\footnotetext{
* Corresponding author: vb_filatov@mail.ru
} 
improves the lateral stiffness of the building. One of the stages of designing high-rise buildings is the calculating of flat slabs for punching. The calculation is aimed at ensuring the constructive safety of the building [8-10], including in the case of progressive collapse. Since the calculation for punching shear has an empirical basis, the carrying out of experimental studies [11-13] is a necessary condition for the improvement of computational methods [14-17]. As the results of experimental studies show [18-20], the punching strength of a slab supported on a rectangular column may be less than that of punching a square column. This effect is a consequence of the non-uniform distribution of deformations along the control perimeter of the punching of a flat reinforced concrete slab supported on a rectangular column. When punching the plate by column of circular crosssection such features of the distribution of deformation is not observed. This peculiarity for rectangular columns was observed experimentally by several researches such as Moe [21], Hawkins et al. [22], Muttoni, Sagaseta et al. [23, 24] and any others. In the experiments of these authors there is a concentration of the strains of concrete slabs in areas near the corners of the columns.

The punching shear strength of flat reinforced concrete slabs depends not only on the aspect ratio of the rectangular cross-section of the column, but also on the ratio of the side of the column cross-section to the effective depth of slab (C/d). In the articles [23, 24] it was shown that with increase of the ratio $\mathrm{C} / \mathrm{d}$ punching shear strength of flat reinforced concrete slabs is reduced.

The punching shear strength of RC flat slabs at rectangular columns can be overestimated if the non-uniform distribution of strains along the control perimeter around the column is neglected in the calculations. Different approaches are used in design codes to determine the punching shear strength of a slab supported on a rectangular column. Design code ACI 318-11 [26] are used correction factor, which depends on the ratio of the sides of the column cross-section. Model Code MC2010 [27] and Swiss design code SIA 262 [28] recommend decreasing the value of the control perimeter, including for a square column, depending on the ratio $\mathrm{C} / \mathrm{d}$. There are other suggestions for improving the calculation methods [16, 17, 23-25]. Calculation methods of codes [29, 30] for punching shear strength of flat slabs the non-uniform distribution of strains along the control perimeter around the column are neglected.

\section{Methods}

Consider the cross-section of a flat plate I-I that passes through the body of a column (fig. 1). At the interface with the column, the slab is an absolutely rigid body in terms of flexural stiffness. The presence of such an absolutely rigid part significantly influences the plate deformation behavior and stress distribution in the interface zone of the plate with the column.

Along the perimeter of the column, a zone of constrained deformations is formed in the plate, due to the presence of a conditional absolutely rigid body in the section of the interface between the plate and the column. Suppose that for a square column the zone of constrained deformations has the form of a circle whose diameter is equal to the diagonal of the square. The maximum value of this zone is in the middle of the face of the column, at the corners of the column the zone is equal to zero. In the case of a rectangular column, the zone of constrained deformations has the shape of an ellipse. The foci of the ellipse are on the short sides of the column, so that the focal parameter is half the short side of the column section. 


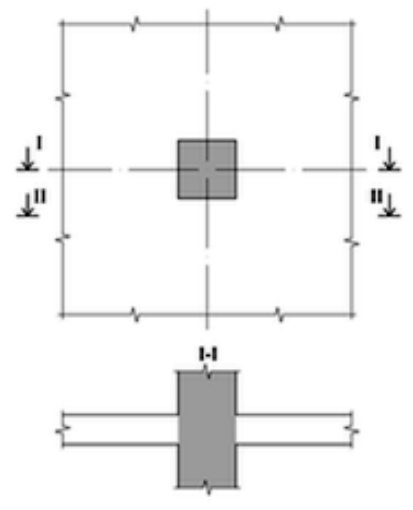

Fig. 1. Fragment of flat plate floor.

On the plate section equal to the width of the column, in the direction of the perpendicular face of the column (radial strains), the zone of constrained deformations does not significantly affect the flexural deformations of the plate. The most significant flexural deformations of the plate vary in the section of the slab along the face of the column in section II-II (fig. 1). The maximum value of strains of the plate is near the corners of the column, the minimum value is in the middle of the face of the column. Thus, the zone of constrained deformations has the greatest influence on the value of tangential strains of the plate.

To estimate the influence of the zone of constrained deformations on the flexural deformations of the plate, let us compare the flexural stiffness of two sections of the plate: from the face of the column to the control perimeter and from the face of the column to the circle denoting the zone of constrained deformations (fig. 2).

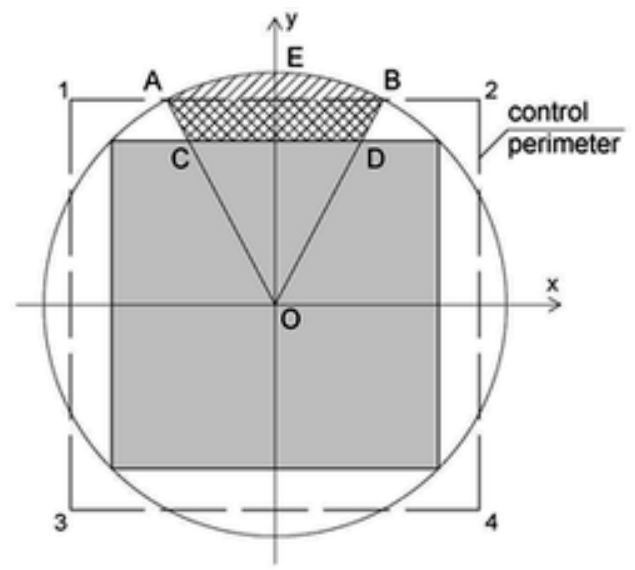

Fig. 2. Constrained deformation zone around square column.

Distance from face of column to the control perimeter will take equal to $0.5 \mathrm{~d}$, in accordance with [30]. Assume that the tangential strains (stresses) of the plate are reduced at the site where the circumference of the area of the constrained deformation beyond the border control perimeter (line $\mathrm{AB}$ ). The reduction of strains proportional to the ratio of moments of inertia relative to the $\mathrm{Y}$ axis of area $\mathrm{ABCD}\left(\mathrm{I}_{\mathrm{cp}}\right)$ and area $\mathrm{AEBCD}\left(\mathrm{I}_{\mathrm{cir}}\right)$.

The value of the control perimeter on the side $1-2$ will also be reduced in proportion to the ratio $\mathrm{I}_{\mathrm{cp}} / \mathrm{I}_{\mathrm{cir}}$. Similarly, the value of the control perimeter decreases and on the other 
three sides of the column section. Assuming a reduced value of the control perimeter, determine the value of the punching force according to the normative method.

The proposed approach makes it possible to determine the influence of the factor $\mathrm{C} / \mathrm{d}$ on the strength of the plate under punching force $(\mathrm{C}$ - column face size, $\mathrm{d}$ - effective depth of slab).

Similarly, it is proposed to take into account the decrease in the control perimeter when the flat plate is punching by a rectangular column. The value of the control perimeter decreases in proportion to the ratio $\mathrm{I}_{\mathrm{cp}} / \mathrm{I}_{\mathrm{cir}}$. The values of $\mathrm{I}_{\mathrm{cp}} / \mathrm{I}_{\mathrm{cir}}$ on the sides $1-2$ and $3-4$ are determined relative to the $\mathrm{Y}$ axis of areas $\mathrm{ABCD}$ и $\mathrm{AEBCD}$, respectively (fig. 3).

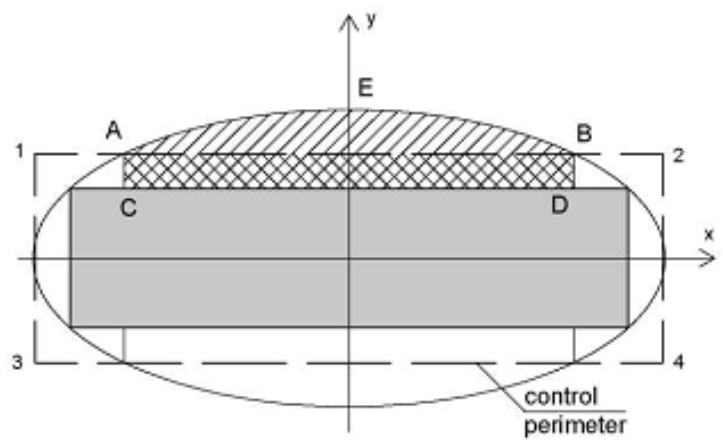

Fig. 3. Constrained deformation zone around rectangular column.

The $\mathrm{I}_{\mathrm{cp}} / \mathrm{I}_{\mathrm{cir}}$ values on the sides $1-2$ and $2-4$ are determined for the respective sections (if any) relative to the $\mathrm{X}$ axis. In this case, when calculating the punching plate, two calculation factors are taken into account - the $\mathrm{C} / \mathrm{d}$ ratio and the ratio of the sides of the rectangular cross section of the column $\mathrm{C}_{\max } / \mathrm{C}_{\min }$.

\section{Results}

In accordance with the proposed approach of considering the influence of structural parameters on the punching shear strength of flat reinforced concrete slabs was determined the dependence of strength of flat slabs under punching on the value of the factor $\mathrm{C} / \mathrm{d}$ (the ratio of the sides of the column cross-section to the effective depth of slab). The change in the punching shear strength of flat slab was evaluated by adjusting the value of the control perimeter in proportion to the ratio $\mathrm{I}_{\mathrm{cp}} / \mathrm{I}_{\mathrm{cir}}$. The ratio of the corrected value of the control perimeter $U_{\text {red }}$ to the initial value control perimeter $U$ is an indicator of the reduction in punching shear strength of flat slab. The dependence of the value $U_{\text {red }} / U$ on the calculated factor $\mathrm{C} / \mathrm{d}$ for a square column is shown in fig. 4.

The strength of the plate under punching by rectangular column will depend on two structural parameters - the ratio of the sides of the column cross-section to the effective depth of slab $\mathrm{C} / \mathrm{d}$ and the ratio of the sides of the rectangular cross section of the column $\mathrm{C}_{\max } / \mathrm{C}_{\min }$. The reduction of punching strength of flat slabs also evaluated against the adjusted and initial values of the control perimeter $U_{\text {red }} / U$. The dependence of $U_{\text {red }} / U$ from the structural parameter $\mathrm{C}_{\max } / \mathrm{C}_{\min }$ for several values of $\mathrm{C}_{\min } / \mathrm{d}(1.13,2.7,5)$ is shown in fig. 5 . 


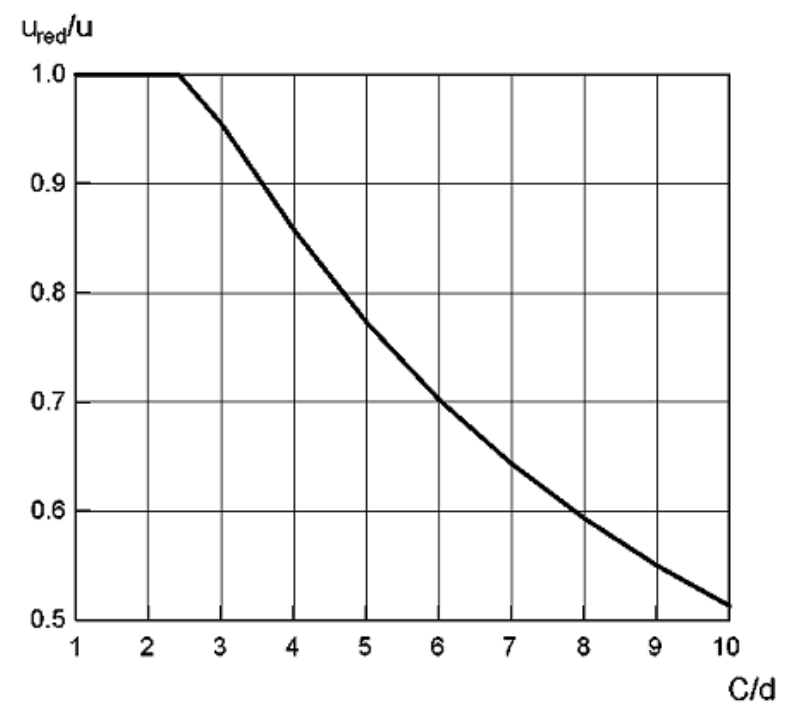

Fig. 4. Reduction of control perimeter for square column due to factor $\mathrm{C} / \mathrm{d}$

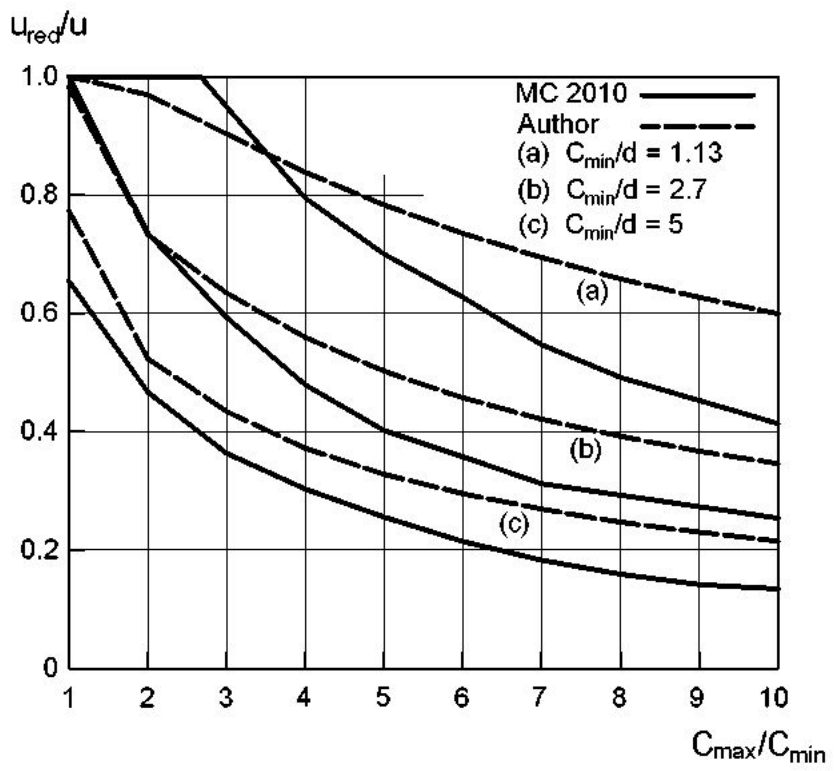

Fig. 5. Comparison of predicted shear-resisting control perimeter using MC2010 and proposed approach.

On fig. 5 also shows the dependence of $U_{\text {red }} / U$ on the structural parameter $C_{\max } / C_{\min }$ obtained in [23] using MC2010 simplified method.

\section{Discussion}

Analysis of the dependence in fig. 4 shows a significant influence of the parameter $\mathrm{C} / \mathrm{d}$ on the punching force to flat slab. With the ratio of the sides of the column cross-section to the effective depth of slab $\mathrm{C} / \mathrm{d}=5$ the reduction in punching shear strength is $23 \%$, at $\mathrm{C} / \mathrm{d}=10$ the strength reduction reaches $49 \%$. When the ratio $\mathrm{C} / \mathrm{d}<2.5$ the decrease in the strength of 
the plate punching by square column is not observed. For value of $\mathrm{C} / \mathrm{d}=3 \mathrm{MC} 2010$ simplified method gives $U_{\text {red }} / U=1$, the proposed approach gives the value of $U_{\text {red }} / U=$ 0.955 , which is a good agreement.

Analysis of the dependence on fig. 5 shows that for small values of $\mathrm{C}_{\min } / \mathrm{d} \approx 1$, the parameter $\mathrm{C}_{\max } / \mathrm{C}_{\min }<2.6$ does not affect the punching shear strength of a flat plate. With an increase in the ratio $\mathrm{C}_{\min } / \mathrm{d}$, a sharp drop in the punching shear strength of the plate occurs. When the value of $\mathrm{C}_{\max } / \mathrm{C}_{\min }=2$, method design code ACI 318-11 [26] does not imply a reduction in strength $\left(\mathrm{U}_{\text {red }} / \mathrm{U}=1\right)$, proposed approach gives the value $\mathrm{U}_{\text {red }} / \mathrm{U}=$ 0.733 and 0.523 for $\mathrm{C}_{\min } / \mathrm{d}=2.7$ and 5, respectively. MC2010 simplified method gives the value $\mathrm{U}_{\text {red }} / \mathrm{U}=0.74$ and 0.46 for $\mathrm{C}_{\mathrm{min}} / \mathrm{d}=2.7$ and 5 , respectively. In general, the proposed approach gives more conservative results compared to the MC2010 simplified method, at $\mathrm{C}_{\max } / \mathrm{C}_{\min }=5$ the difference is $20-25 \%$.

\section{Conclusions}

This paper presents the results from the analytical research on punching shear of flat slabs supported by square and rectangular columns. Proposed approach was investigated to assess the shear-resisting control perimeter due to the influence of parameters $\mathrm{C} / \mathrm{d}$ and $\mathrm{C}_{\max } / \mathrm{C}_{\min }$. The main conclusions are the following:

- The effect of parameters $\mathrm{C} / \mathrm{d}$ (the ratio of the side of the column cross-section to the effective depth of slab) and $\mathrm{C}_{\max } / \mathrm{C}_{\min }$ (the ratio of the sides of the rectangular cross section of the column) on the value of the punching force of a flat plate is significant enough and should be taken into account in design codes. Proposed approach is phenomenological and allows evaluating the effect of structural parameters on the punching strength of a flat plate on the basis of a physical model by adjusting the value of the control perimeter of the slab.

- The results from the analytical research gives more conservative results compared to the MC2010 simplified method [27] and shear field analysis or a method based on the contact pressure at the support area [23]. Analysis of research results allows identifying ranges of structural parameters, when the design codes calculation methods do not capture a possible reduction in the bearing capacity of the slab for punching that allows us to make a conclusion about the necessity of further improvement of design codes.

- The results from the analytical research on punching shear of flat slabs supported by square and rectangular columns, are confirmed the previously proposed hypothesis about the presence a zone of constrained deformation in the slab, which located along the perimeter of a square or rectangular column. The deformation features of the plate in this zone affect the distribution of strains along the control perimeter around the column and the plate resistance by the punching force, respectively. The results of the study presented in this article, as well as in $[14,18,20,23]$ confirm the necessity of taking into account the structural parameters in calculating the punching strength of flat slabs and further improving the normative calculation procedures.

\section{References}

1. E. N. Kodysh, N. N. Trekin, D. N. Trekin, Concrete and reinforced concrete - glance at future: III All-Russian (II International) Conference on concrete and reinforced concrete, 1, 69-75 (2014)

2. V. I. Travush, V. I. Kolchunov, N. V. Klyueva, Industrial and civil engineering, 3, 4$11(2015)$

3. V. I. Travush, S. G. Emel'yanov, V. I. Kolchunov, Industrial and civil engineering, 7, 20-27 (2015) 
4. A.G. Tamrazyan, Industrial and civil engineering, 7, 26-27 (2012)

5. V. P. Popov, D. V. Popov, A. Yu. Davidenko, MATEC Web of Conferences, 86, 01014 (2016)

6. A. O. Mateyko, Vestnik of SSUACE, 23(3), 74-78 (2016) DOI: 10.17673/Vestnik.2016.03.12

7. V. P. Generalov, E. M. Generalova, Vestnik of SSUACE, 10(2), 12-16 (2013) DOI: 10.17673/Vestnik.2013.02.2

8. N. I. Karpenko, S. N. Karpenko, Zhilishchnoe stroitel'stvo, 6, 16-20 (2016)

9. V. B. Filatov, A. A. Suvorov, Procedia Engineering, 153, 144-150 (2016)

10. A. G. Tamrazyan, Yu. N. Zvonov, Industrial and civil engineering, 7, 24-28 (2016)

11. N. N. Trekin, D. A. Pekin, Industrial and civil engineering, 7, 17-20 (2014)

12. A. N. Bolgov, A. Z. Sokurov, Concrete and reinforced concrete - glance at future: III All-Russian (II International) Conference on concrete and reinforced concrete, 4, 139149 (2014)

13. A. N. Bolgov, D. M. Yakimovich, Concrete and reinforced concrete - glance at future: III All-Russian (II International) Conference on concrete and reinforced concrete, $\mathbf{1}$, 224-233 (2014)

14. A. Muttoni, ACI Struct. J., 105(4), 440-450 (2008)

15. C. E. Broms, ACI Struct. J., 87(3), 292-304 (1990)

16. V. B. Filatov, Bulletin of civil engineers, 5(40), 80-84 (2013)

17. V. B. Filatov, Proceedings of the Samara scientific center of the Russian Academy of Sciences, 16(4-3), 646-649 (2014)

18. T. Susanto, H. K. Cheong, K. L. Kuang, J. Z. Geng, ACI Struct. J., 101(5), 678-687 (2004)

19. V. B. Filatov, E. P. Bubnov, MATEC Web of Conferences, 86, 01007 (2016)

20. V. B. Filatov, E. P. Bubnov, Industrial and civil engineering, 2, 86-91 (2017)

21. J. Moe, Dev. dep. bul. D47, PCA (1961)

22. N. M. Hawkins, H. B. Falssen, R. C. Hinojosa, ACI Spec. Publ., SP-30, 127-146 (1971)

23. J. Sagaseta, L. Tassinari, M. Fernandez Ruiz, A. Muttoni, Eng. Struct., 77, 17-33 (2014)

24. J. Sagaseta, A. Muttoni, M. Fernandez Ruiz, L. Tassinari, Mag. Conc. Res., 63(6), 441-457 (2011)

25. V. B. Filatov, Proceedings of the Samara scientific center of the Russian Academy of Sciences, 16(4-3), 642-645 (2014)

26. ACI 318-11, Building code requirements for structural concrete and commentary, (Farmington Hills, MI, ACI, 2011)

27. fib Model Code for Concrete Structures 2010, 434 (Ernst \& Sohn, Berlin, 2013)

28. Code 262 for concrete structures (Zürich, SIA, 2013)

29. BS 8110, Part 1: structural use of concrete, (London, BSI, 1997)

30. SP 63.13330.2012, Concrete and reinforced concrete. Design code, (Moscow, 2012) 